\title{
Detection of Fungal Contagion in Food Items Using Enhanced Image Segmentation
}

\author{
B. K. Mishra, A. K. Rath, P. K. Tripathy
}

Abstract: Today the consumer demands for superior quality and safe food products. In order to obtain healthier products we need to emphasize on superior detection capabilities to identify any presence of foreign materials on them which are responsible for making them unhygienic. Image segmentation is one such technique which is vastly employed in such domains. It identifies the affected portion from the other regions. Hence, we made an effort to apply image segmentation to discover the existence of fungal contagion in food items. In this paper, an attempt has been made to use clustering as an approach in image segmentation. Few improved cluster-based image segmentation techniques like K-Means, MCKM, FEKM and FECA were used on quite a variety of food items to detect the existence of any kind of fungal growth on their surface. The results segmentation obtained were analyzed to verify their effectiveness by using few known performance measures including SC, RMSE, PSNR, MSE, MAE and NAE. The various food images were segmented to obtain both their gray scale and colored results. As per our anticipation, the outcome of FECA based segmentation is by far much sounder in contrast to the other methods. More or less every value of chosen quality measures offer encouraging results for FECA based segmentation technique as compared to the others, which implies accurate identification of fungal growth on food surfaces was achievable.

Keywords: FECA, FEKM, Fungus detection, Image segmentation, K-Means, MCKM.

\section{INTRODUCTION}

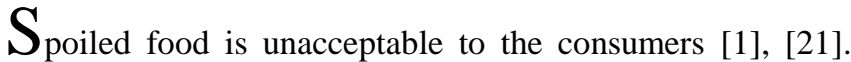
They are caused due to the presence of bacteria, viruses, fungi (mold and yeast), and parasites. Fungus is present virtually in every surroundings. They can cause allergic reactions, digestive disorders and can make us sick if are consumed directly through food items. Most often they are found in food stuffs like cake, bread, cheese, nuts, buns etc. If the food is heavily invaded by fungal growth [11], their presence can be detected by the naked eyes to some extent - fluffy greenish or brownish dots on bread, gray fur-like structures on cakes, white dusty-like growth on cheese etc. However, these

Revised Manuscript Received on October 30, 2019.

* Correspondence Author

Bikram Keshari Mishra*, Department of Computer Science and Engineering, Veer Surendra Sai University of Technology, Burla, India. Email: bikrammishra2012@gmail.com

Amiya Kumar Rath, Department of Computer Science and Engineering, Veer Surendra Sai University of Technology, Burla, India Email: akrath_cse@vssut.ac.in

Pradyumna Kumar Tripathy, Department of Computer Science and Engineering, Silicon Institute of Technology, Bhubaneswar, India.

Email: pradyumnatripathy@gmail.com

(C) The Authors. Published by Blue Eyes Intelligence Engineering and Sciences Publication (BEIESP). This is an open access article under the CC BY-NC-ND license (http://creativecommons.org/licenses/by-nc-nd/4.0/) patches are not visible at the initial stages of their growth. If minutely observed using high-end microscopes their presence may be discovered to some extent. But, this will be expensive, time consuming and practically not feasible to be employed in a real life scenario. In that case, the application of image segmentation can be a blessing and can effectually trace out the tainted areas [22] and intimate us that the food product has been spoiled and not to be consumed.

Image segmentation [6] is usually applied to obtain the essential features from the images. The image pixels with analogous RGB features are grouped into the same region. In this way the segmented portions can be traced out depending on our area of interest. In this paper, we have worked towards the cluster-based image segmentation methods for grouping the pixels with similar intensity together. This approach is pretty simple and yields precise results. Frequent studies are conducted by academia focusing on advent of emerging technologies of food quality and security. A few novel approaches pertinent to this paper are presented below.

The modern application of image processing in the realm of agriculture and food were reviewed by [3], [17]. According to them, computer vision systems are now used in engineering and production units for quality evaluation and offers economic, sanitized, reliable and objective assessment. The microbial variety of ten contaminated precooked pizza samples were studied by [2]. The efficiency of a broad-spectrum pulsed UV ray for the refinement of Penicillium roqueforti, a leading mold for spoiling bakery products was calculated. The result confirmed that pulsed light is a potential method for minimizing contamination in bakery industry. Image processing means to examine the visibility of mold on bread using RGB, HSV and gray scale channel were suggested by [10]. The experiments showed that the uses of negative ions were fruitful in controlling of mold growth on bread. "Ref. [7]" conducted various image and sensory analysis and came up with certain results which are based on quality degradation of bakery products. They used image analysis to accurately estimate any variations in colour and shape of the product during the storage time. Results obtained shows that this method is quite effective for measuring the shelf life trends of any bakery item.

A method to resolve the difficulty of generality-based image segmentation [9] is used in which the performance evaluations of diverse cluster-based image segmentation methods are done. "Ref. [4]" suggested a method to automatically rank the diseases on pomegranate leaves. An image processing technique to deal with the issue of plant pathology which is disease grading was proposed by them to obtain any disease spots on the leaves and fruits. "Ref. [5]" proposed a defect segmentation of fruits with regard to their colour features using K-means method. 
Clustering was done to the image pixels and the clustered masses were grouped to a specified number of sections. It was observed that the computational efficiency was enhanced by means of feature extraction. A method was proposed by [19] for examining the crops for identification of any diseases in them using GSM and remote sensing. Using this technique they were able to detect the presence of fungal diseases in crops much early. Based on their RGB colour and local binary pattern (LBP), [13] suggested a way for classification of vegetables using a multilayer neural network structure. Experiments illustrated a classification accuracy of $93.3 \%$ with different vegetables. An algorithm for colour enhancement of low resolution digital images was presented by [8]. They executed the clock algorithm in their method which gave better results, as it gets information from user and surrounding of the image.

These pioneering works by eminent researchers were the key factors for which we were enthused to work in this domain of image segmentation and project an effectual model which can benefit our suppliers and consumers in successfully detecting the presence of fungus on the surface of food products and taking effective measures thereafter thus restraining their wastage of product, time and money. In this work, we have explored cluster-based image segmentation methods like traditional K-Means [12], Enhanced Clustering Algorithm (FECA) [15], Modified Center K-Means (MCKM) [14] and Far Efficient K-Means (FEKM) [16] on different kinds of frequently used food stuffs. The pros and cons of each method used for image segmentation are discussed. Few known performance measures viz, SC, RMSE, PSNR, MSE, MAE and NAE were used to check the quality of output segmented images. The objective behind choosing a few of them is to get precise segmented results so that even the preliminary fungal growth can be traced out, and there should not arise any biasness on the effectiveness of the segmentation methods. We have also recorded the computation speed that each algorithm takes to meet their convergence.

The following are the contributions of this paper:

a) Analyzing the segmentation results obtained from K-Means, suggested MCKM, FEKM \& FECA methods.

b) Creation of gray scale and colour segmentation to detect any existence of fungus on the surface of food stuffs.

c) Executing the methods on different array of frequently used food products.

\section{A. Approach}

This work is carried out in the following manner: before the food items are placed at their respective stalls in a retail shop, they are placed on a conveyor belt and passed through few cameras installed at different angles where their images are captured. These images are fed to a computer which runs a segmentation algorithm where the captured images are clustered into different colour groups. The results of segmentation can determine the fungal affected food parts from the real one, which were not detected initially by the naked eyes. We can employ different colour group formation as per the requirement for comprehensible identification of the infected food parts. This is illustrated in Fig. 1.

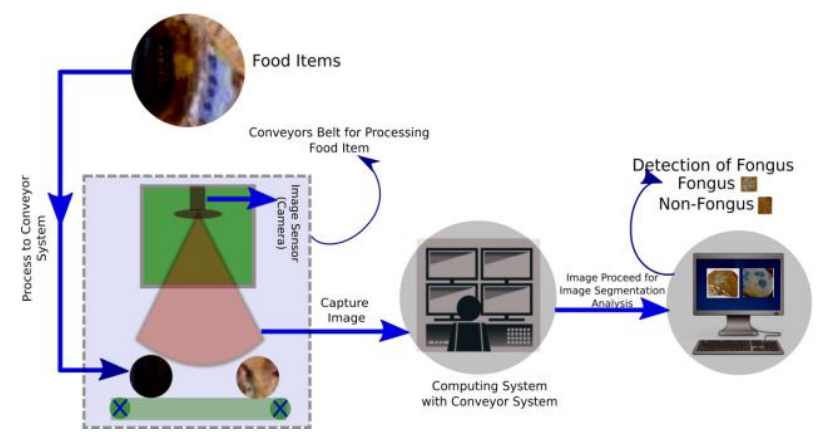

Fig.1. Process employed for detection of fungus from food

\section{B. Performance Measures}

The clarity of segmentation obtained, configuration of fine segmented groups formation and limiting the amount of noise in the segmented image are few important factors that are considered for image segmentation. These aspects determine how efficiently the affected parts in food items caused by fungus are discovered in different food items. A few standard performance measures are considered in this research to determine the effectiveness of the output obtained from segmentation. They are as follows:

\section{i. Structural Content (SC)}

SC measures the similarity of two digital images by means of correlation function. It is possible to determine a closer alliance between two images. A lesser value of SC implies the image is of superior quality. SC measure is given by:-

$$
\mathrm{SC}=\sum_{\mathrm{i}=1}^{\mathrm{m}} \sum_{\mathrm{j}=1}^{\mathrm{n}} \mathrm{in}(\mathrm{i}, \mathrm{j})^{2} / \sum_{\mathrm{i}=1}^{\mathrm{m}} \sum_{\mathrm{j}=1}^{\mathrm{n}} \operatorname{seg}(\mathrm{i}, \mathrm{j})^{2}
$$

where, in $(i, j)$ and $\operatorname{seg}(i, j)$ are input source image and target segmented image, and $m \& n$ are number of image pixels present in rows and columns respectively.

\section{ii. Root Mean Square Error (RMSE)}

RMSE [18], [23] is used to assess the quality of segmented images. It determines the difference in the results likely to be obtained by a model with those which are actually present in it. RMSE is given by:-

$$
\text { RMSE }=\sqrt{\frac{1}{m^{*} n}\left[\frac{\sum_{i=1}^{m} \sum_{j=1}^{n}[i n(i, j)]^{2}}{\sum_{i=1}^{m} \sum_{j=1}^{n}[\operatorname{in}(i, j)-\operatorname{seg}(i, j)]^{2}}\right]}
$$

A smaller value determined from RMSE suggests that the image is of finest quality.

\section{iii. Peak Signal-to-Noise Ratio (PSNR)}

PSNR is used to access the image quality when it is spoiled due to noise or haziness. The value of PSNR is obtained by calculating the RMSE between the intensity of each pixels and then finding the ratio of the maximum possible intensity to the calculated result of RMSE. A small value of PSNR implies the image is of poor quality. PSNR is defined by: 


$$
\text { PSNR }=20 \log _{10}\left(\frac{\mathrm{N}}{\mathrm{RMSE}}\right) \mathrm{dB}
$$

where, $N$ is the maximum pixel intensity of the image.

\section{iv. Mean Square Error (MSE)}

MSE measures the difference in the filtered and the noisy image [20]. If the MSE value is larger, then resultant image produced is a degraded one. MSE is defined by the equation:

MSE $=1 / \mathrm{M} * \mathrm{~N} \sum_{\mathrm{i}=1}^{\mathrm{M}} \sum_{\mathrm{j}=1}^{\mathrm{N}}\left((\mathrm{x}(\mathrm{i}, \mathrm{j})-\mathrm{y}(\mathrm{i}, \mathrm{j}))^{2}\right.$

where, $x(i, j)$ is the filtered and $y(i, j)$ is the noisy image.

\section{v. Mean Absolute Error (MAE)}

There are situations when captured images get haze due to camera quality, atmospheric commotion etc. Here, MAE offers an improved solution to update the de-blurring effect. MAE measure is given by:

$M A E=1 / M * N \sum_{i=1}^{M} \sum_{j=1}^{N} \mid(x(i, j)-y(i, j) \mid$

A larger MAE value indicates that image is of poor quality.

\section{vi. Normalised Absolute Error (NAE)}

NAE is quantified as how far is the decompressed image from the original image with zero being the ideal value. Larger value of NAE indicates poor quality of the image. NAE is given by:

$$
N A E=\sum_{i=1}^{M} \sum_{j=1}^{N}\left(\mid(x(i, j)-y(i, j) \mid) / \sum_{i=1}^{M} \sum_{j=1}^{N}(\mid(x(i, j) \mid)\right.
$$

\section{METHOD}

The principal idea behind this research is to separate out the image pixels of the food items from one another applying clustering and identify the portion of the items which may have been infected due to presence of fungus in them from the rest part. We have used clustering in image segmentation to set apart a certain input image into different clusters so that the pixels placed in one cluster resemble familiar characteristics to those present in other clusters. The essence of clustering is carried out by taking different values of cluster centers to produce different colour-groups. A wide range of cluster-based image segmentation approaches used in this paper is discussed here.

\section{A. Method - I: K-Means for Image Segmentation}

The K-Means is a simplest unsupervised algorithm which was proposed by J. Mac Queen in 1967. Initially, the required number of segments to be formed is decided. The initial cluster center pixels are picked randomly. At the end of each pass, each pixel is dispatched and assigned to the nearby partition based on minimum Euclidean distance measure. The Euclidean measure calculates the distance from each pixel $p_{i}$ to the cluster centers $c_{i}$ which is given by:

$$
D_{i j}=\left(\sum_{l=1}^{d}\left|x_{i l}-x_{j l}\right|^{2}\right)^{1 / 2}
$$

Each food image pixel has its own RGB values. Each pixel's RGB is compared with the previously selected clusters centers RGB value and their distance is recorded. The pixel whose distance is minimum from a cluster center is assigned to that cluster. Then, the mean RGB value of all pixels within a cluster is determined to obtain the new center. This procedure is recurred until the pixels no longer vary their allocated clusters.

This method of achieving the desired clusters gives encouraging results in quick time if the initial random selections of pixels to form the centers are by chance perfectly picked otherwise, incorrectly selected pixel to frame the initial center may create malevolent segmentation where a portion of the food item may wrongly show as fungal affected and sometimes may also go to that extent of showing the complete food item as unaffected which may not be the real case. Now, keeping this issue in mind we have modified the basic approach of K-Means and have worked out on different ways to get genuine centers so that they produce effective outcome of clustering and our motive of detecting the real fungal contagion part of food items is accomplished.

\section{B. Method - II: Modified Center K-Means (MCKM) for Image Segmentation}

In MCKM [14], initially the number of partitions $K$ to be framed for any food item image is decided by the user. The Euclidean distances from all pixels to the initial pixel is measured, and are stored in ascending order. The entire image matrix is then alienated into $K$ segments and the initial pixel in each segment is chosen as the cluster center. The mean pixels within a segment determine the new center. The entire process is repeated till convergence.

\section{Pseudo-code:}

MCKM (img_data, k):

1. add img_data[1] to centroid[ ]

// Create a list of intensity difference from img _data[1] to all other img_data present in the image matrix

2. for each pix in img _data:

3. add euclead_diff (img_data[1], pix ) to intent_diff [ ]

4. $\quad$ sort img_data w.r.t intent_diff [ ]

5. split img_data into $k$ groups

6. add mean pixels of each group to centroid[ ]

7. return centroid

8. Execute K-Means for cluster formation

9. end

\section{Method - III: Far Efficient K-Means Algorithm (FEKM) for Image Segmentation}

FEKM [16] is a novel method for efficiently selecting the initial cluster centers. The pseudo-code is outlined below:

\section{Pseudo-code:}

get_center(img_data, $\mathrm{k}$ ):

// Determining two pixels with max. intensity difference

1. for pix_i in img_data:

for pix_j in img_data:

inten_diff $[i, j]=$ euclea_dist(pix_i, pix_j)

2. center[1], center[2] $=\max ($ inten_diff $[i, j])$

//Grouping pixels with similar intensity w.r.t center[1] and center [2] till a threshold is reached 3. set $\mathrm{i}=0$ 
4. while $(\mathrm{i}<(0.5 *$ (img_size $/ \mathrm{k})$ ):

// threshold

intent1 = euclea_dist(center[1], img_data[i])

intent2 = euclea_dist(center[2], img_data[i])

if (intent1 <= intent2):

addimg_data[i] to cluster[1]

removeimg_data[i] from img_data

else:

addimg_data[i] to cluster[2]

removeimg_data[i] from img_data

$$
\mathrm{i}=\mathrm{i}+1
$$

$/ /$ end of while loop

// Updating cluster centers

5. center[1] = mean(cluster[1])

6. center[2] $=$ mean $($ cluster[2])

//Selecting the remaining $(k-2)$ centers

7. set $\mathrm{i}=3$

8. while $(\mathrm{i}<=\mathrm{k})$ :

for each ci in range( $0, i)$ :

set $\mathrm{j}=0$

for each pix in img_data:

if $\mathrm{ci}=0$ :

intent_diff = euclea_dist (center[ci], pix) addintent_diff to min_list[

else:

intent_diff=euclea_dist(center[ci], pix)

if (min_list[j] > intent_diff):

min_list $[j]=$ intent_diff

$\mathrm{j}=\mathrm{j}+1$

add max(min_list) to center

// end of while loop

9. return center

10. Execute K-Means for formation of clusters.

11. end

In step (1) and (2) the Euclidian distance amid each pair of pixels in the food image matrix is calculated and the extreme pair of pixels found is treated as initial cluster center. Step (4) deals with assigning the pixels which are nearest to these clusters found from step (1). Step (8) is meant to determine the remaining $(K-2)$ centers such that, $\max$ ( $\min$ ( distance ( $\left.\left.\left.\left\{d_{i}, c_{1}\right\},\left\{d_{i}, c_{2}\right\}\right)\right)\right)$ criteria is satisfied. Once the required centroids are determined, normal K-Means algorithm is executed to perform the necessary cluster formation.

\section{Method - IV: Far Enhanced Clustering Algorithm (FECA) for Image Segmentation}

This algorithm [2018] is carried out with an effort to improve the effectiveness of K-Means, FEKM and MCKM used for image segmentation. The sole purpose of this technique is to obtain much improved clustering effect so that it becomes easier to clearly identify the areas in food items which are spoiled due to the presence of fungus in them. The algorithm operates in two phases. In Phase I, the algorithm finds the near optimal $K$ cluster centers by invoking the procedure FEKM (step 1 to 9) as discussed in Method - III, and Phase II targets at performing the effective segmentation.

Phase I - Invoke FEKM for discovering K cluster centers.

Phase II - Perform the requisite segmentation
Pseudo-code:

1. Initially, each img_data is assigned to its nearby centroids

2. Construct two lists certer_ref $=$ [ ] and inten_diff_ref $=[$ ] //Creating center_ref [ ]

3. for $\mathrm{p}$ in img_data:

set $i=0$

for $\mathrm{c}$ in cluster:

if $\mathrm{p}$ in $\mathrm{c}$ :

add $\mathrm{i}$ to center_ref

$\mathrm{i}=\mathrm{i}+1$

// end of for loop

//Creating inten_diff_ref [ ]

4. set $i=0$

5. for $p$ in img_data:

addeuclea_dist (center[center_ref[i], p) $\mathrm{i}=\mathrm{i}+1$

6. Recalculate the centroids by taking the mean of pixels in cluster

7. Repeat till convergence:

set $\mathrm{i}=0$

for $p$ in img_data:

in_diff = euclea_dist (center[center_ref [i] ], p)

if $($ in_diff $>$ inten_diff_ref [i] ):

set inten_diff_list $=[$ ]

for $\mathrm{cl}$ in center:

addeuclea_dist (cl, p) to inten_diff_list

inten_diff_ref[i] = min (inten_diff_list)

remove $\mathrm{p}$ from its present cluster

center_ref[i] = index of (min (inten_diff_list))

add $\mathrm{p}$ to cluster [center_ref [i]]

$\mathrm{i}=\mathrm{i}+1$

//end of for loop

Recalculate the cluster centers by taking the mean

8. end

In step (3) of Phase II, a list center_ref [ ] is created to store the reference of the cluster number into which a pixel belongs. Similarly, in step (4) inten_diff_ref [ ] is formed to store the Euclidean distance of each pixel from the cluster center. In step (7) an evaluation is carried out to check whether a pixel will continue to stay in its original cluster segment or will be positioned in a new cluster. This step is repeated until convergence is attained. Finally, the cluster centers are re-evaluated by taking the mean of all pixels present in a segment.

By means of all these methods it is possible to get the segmented images of different varieties of input food image. The segmented result can be achieved for any number of cluster formations. The eminence of segmentation achieved for every values of $K$ are examined further by using several performance quality measures.

\section{RESULTS AND DISCUSSION}

All the above discussed methods are tested for discovering any presence of fungal growth on food products available in general stores. Deliberately to examine the segmentation outcome, we have considered some food items which are already fungal affected. If we look minutely at them with the help of a magnifying glass we can observe the existence of

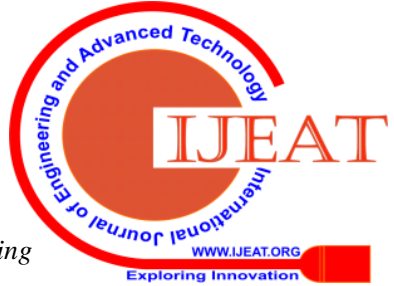


tiny white spots or minor brownish patches on them. But, these can be confirmed once the segmentation result also agrees on it. The quality of segmentation plays a major role in this aspect. Hence, we have implemented few measures including SC, PSNR, RMSE, MSE, NAE and MAE in our algorithms to test the effect of segmentation.

As the food items arrive fully packed and also they vary in type, colour, shape and sizes to the retail shop, we have placed few cameras to take pictures of every possible angle of them. Further, the images captured were resized and were transformed into (400X400) pixel resolution for gaining reasonable computation speed. We have conducted our experiment with more than ten different varieties of food items including sweet breads, fruit breads, yeast bread, cheese, cakes, buns, nuts etc. and for each item we have also carried out our test by considering at least $3-4$ images each. A few of them are shown in Fig. 2 and 3 respectively. Experiment was conducted with different values of cluster formation $K$. In this paper, we have presented only $K=2$ and $K=3$ for segment formation with various techniques.

\section{i. Experiment 1:}

The first experiment was conducted by taking different varieties of breads. Here, we have experimented with four images of bread. The breads were places on the conveyor belt and made to pass through the cameras installed. Different images were captured at different angles and then were given as input to all the discussed methods. These methods segmented the original bread image into both gray-scale and three-colour segments in order to present a clear picture of the defect portion from the original ones. Then the quality of segmented results was tested using SC, RMSE, PSNR, MSE, MAE and NAE as shown below:

Table I:

(a) MSE on different images of bread (with $\mathrm{K}=2$ )

\begin{tabular}{lcccc}
$\begin{array}{l}\text { Images of } \\
\text { Bread }\end{array}$ & $\begin{array}{c}\text { K-Mean } \\
\mathbf{s}\end{array}$ & $\begin{array}{c}\text { MCKM } \\
\text { Seg. }\end{array}$ & $\begin{array}{c}\text { Seg. } \\
\text { FEKM }\end{array}$ & $\begin{array}{c}\text { FEC. } \\
\text { Seg. }\end{array}$ \\
\hline 2_400.jpg & 22.319 & 22.638 & 22.225 & 20.001 \\
5_400.jpeg & 39.377 & 34.06 & 30.566 & 18.328 \\
Ddbread.png & 6.363 & 6.394 & 6.062 & 5.022 \\
$\begin{array}{l}\text { Ddbread2.pn } \\
\text { g }\end{array}$ & 3.218 & 3.415 & 3.323 & 3.014 \\
\hline
\end{tabular}

(b) MSE on different images of bread (with $\mathrm{K}=3$ )

\begin{tabular}{|c|c|c|c|c|}
\hline $\begin{array}{l}\text { Images of } \\
\text { Bread }\end{array}$ & $\begin{array}{c}\text { K-Mean } \\
\text { s } \\
\text { Seg. } \\
\end{array}$ & $\begin{array}{c}\text { MCKM } \\
\text { Seg. }\end{array}$ & $\begin{array}{c}\text { FEKM } \\
\text { Seg. }\end{array}$ & $\begin{array}{c}\text { FECA } \\
\text { Seg. }\end{array}$ \\
\hline 2_400.jpg & 22.319 & 22.638 & 22.225 & 20.001 \\
\hline 5_400.jpeg & 39.377 & 34.06 & 30.566 & 18.328 \\
\hline $\begin{array}{l}\text { Ddbread.png } \\
\text { Ddbread2.pn }\end{array}$ & 6.363 & 6.394 & 6.062 & 5.022 \\
\hline g & 3.218 & 3.415 & 3.323 & 3.014 \\
\hline
\end{tabular}

(c) RMSE on different images of bread (with $\mathrm{K}=2$ )

\begin{tabular}{lcccc}
\hline $\begin{array}{l}\text { Images } \\
\text { of } \\
\text { Bread }\end{array}$ & $\begin{array}{c}\text { K-Means } \\
\text { Seg. }\end{array}$ & $\begin{array}{c}\text { MCKM } \\
\text { Seg. }\end{array}$ & $\begin{array}{c}\text { FEKM } \\
\text { Seg. }\end{array}$ & $\begin{array}{c}\text { FECA } \\
\text { Seg. }\end{array}$ \\
\hline $\begin{array}{l}\text { 2_400.jp } \\
\text { g }\end{array}$ & 4.724 & 4.701 & 4.779 & 4.690 \\
$\begin{array}{l}5 \_400 . j p \\
\text { eg }\end{array}$ & 6.275 & 2.015 & 3.672 & 4.044 \\
$\begin{array}{l}\text { Ddbread } \\
\text {.png }\end{array}$ & 2.522 & 2.702 & 2.455 & 2.241 \\
$\begin{array}{l}\text { Ddbread } \\
\text { 2.png }\end{array}$ & 1.799 & 1.793 & 1.781 & 1.730 \\
\hline
\end{tabular}

(d) RMSE on different images of bread (with $\mathrm{K}=3$ )

\begin{tabular}{lcccc}
\hline $\begin{array}{l}\text { Images of } \\
\text { Bread }\end{array}$ & $\begin{array}{c}\text { K-Means } \\
\text { Seg. }\end{array}$ & $\begin{array}{c}\text { MCKM } \\
\text { Seg. }\end{array}$ & $\begin{array}{c}\text { FEKM } \\
\text { Seg. }\end{array}$ & $\begin{array}{c}\text { FECA } \\
\text { Seg. }\end{array}$ \\
\hline 2_400.jpg & 4.233 & 4.417 & 4.336 & 4.208 \\
5_400.jpeg & 1.700 & 3.388 & 3.094 & 3.362 \\
Ddbread.png & 4.421 & 2.600 & 2.535 & 1.875 \\
$\begin{array}{l}\text { Ddbread2.pn } \\
\text { g }\end{array}$ & 2.946 & 1.240 & 1.219 & 1.011 \\
\hline
\end{tabular}

(e) PSNR on different images of bread (with $\mathrm{K}=2$ )

\begin{tabular}{lcccc}
\hline $\begin{array}{l}\text { Images of } \\
\text { Bread }\end{array}$ & $\begin{array}{c}\text { K-Means } \\
\text { Seg. }\end{array}$ & $\begin{array}{c}\text { MCKM } \\
\text { Seg. }\end{array}$ & $\begin{array}{c}\text { FEKM } \\
\text { Seg. }\end{array}$ & $\begin{array}{c}\text { FECA } \\
\text { Seg. }\end{array}$ \\
\hline 2_400.jpg & 34.643 & 32.643 & 33.791 & 34.707 \\
5_400.jpeg & 32.178 & 42.044 & 41.497 & 42.062 \\
Ddbread.png & 40.093 & 40.439 & 40.736 & 41.121 \\
Ddbread2.pn & 43.054 & 43.006 & 45.171 & 43.339 \\
g & & &
\end{tabular}

(f) PSNR on different images of bread (with $\mathrm{K}=3$ )

\begin{tabular}{lcccc}
\hline $\begin{array}{l}\text { Images of } \\
\text { Bread }\end{array}$ & $\begin{array}{c}\text { K-Means } \\
\text { Seg. }\end{array}$ & $\begin{array}{c}\text { MCKM } \\
\text { Seg. }\end{array}$ & $\begin{array}{c}\text { FEKM } \\
\text { Seg. }\end{array}$ & $\begin{array}{c}\text { FECA } \\
\text { Seg. }\end{array}$ \\
\hline 2_400.jpg & 35.597 & 35.227 & 35.071 & 35.546 \\
5_400.jpeg & 43.520 & 37.531 & 39.402 & 37.596 \\
Ddbread.png & 35.220 & 44.047 & 45.517 & 46.668 \\
Ddbread2.pn & 38.745 & 40.257 & 40.996 & 44.542 \\
g & & &
\end{tabular}

(g) MAE on different images of bread (with $\mathrm{K}=2$ )

\begin{tabular}{lcccc}
\hline $\begin{array}{l}\text { Images of } \\
\text { Bread }\end{array}$ & $\begin{array}{c}\text { K-Means } \\
\text { Seg. }\end{array}$ & $\begin{array}{c}\text { MCKM } \\
\text { Seg. }\end{array}$ & $\begin{array}{c}\text { FEKM } \\
\text { Seg. }\end{array}$ & $\begin{array}{c}\text { FECA } \\
\text { Seg. }\end{array}$ \\
\hline 2_400.jpg & 141.360 & 141.081 & 140.863 & 135.140 \\
5_400.jpeg & 66.747 & 61.252 & 60.556 & 58.072 \\
Ddbread.png & 67.650 & 65.694 & 60.001 & 62.886 \\
$\begin{array}{l}\text { Ddbread2.pn } \\
\text { g }\end{array}$ & 49.868 & 48.458 & 48.753 & 47.687 \\
\hline
\end{tabular}

(h) MAE on different images of bread (with $\mathrm{K}=3$ )

\begin{tabular}{lcccc}
$\begin{array}{l}\text { Images of } \\
\text { Bread }\end{array}$ & $\begin{array}{c}\text { K-Means } \\
\text { Seg. }\end{array}$ & $\begin{array}{c}\text { MCKM } \\
\text { Seg. }\end{array}$ & $\begin{array}{c}\text { FEKM } \\
\text { Seg. }\end{array}$ & $\begin{array}{c}\text { FECA } \\
\text { Seg. }\end{array}$ \\
\hline 2_400.jpg & 122.255 & 130.405 & 124.562 & 118.124 \\
5_400.jpeg & 50.215 & 88.395 & 67.891 & 87.707 \\
$\begin{array}{l}\text { Ddbread.pn } \\
\text { g }\end{array}$ & 112.372 & 84.396 & 72.148 & 55.725 \\
$\begin{array}{l}\text { Ddbread2.p } \\
\text { ng }\end{array}$ & 69.887 & 23.390 & 38.247 & 43.497 \\
\hline
\end{tabular}

(i) NAE on different images of bread (with $\mathrm{K}=2$ )

\begin{tabular}{llccc}
\hline $\begin{array}{l}\text { Images of } \\
\text { Bread }\end{array}$ & $\begin{array}{c}\text { K-Means } \\
\text { Seg. }\end{array}$ & $\begin{array}{c}\text { MCKM } \\
\text { Seg. }\end{array}$ & $\begin{array}{c}\text { FEKM } \\
\text { Seg. }\end{array}$ & $\begin{array}{c}\text { FECA } \\
\text { Seg }\end{array}$ \\
\hline 2_400.jpg & 0.993 & 0.901 & 0.956 & 0.879 \\
5_400.jpeg & 1.066 & 0.715 & 0.553 & 0.305 \\
Ddbread.png & 0.356 & 0.399 & 0.324 & 0.331 \\
Ddbread2.pn & 0.528 & 0.436 & 0.337 & 0.231 \\
g & & & & \\
\hline
\end{tabular}

(j) NAE on different images of bread (with $\mathrm{K}=3$ )

\begin{tabular}{lcccc}
\hline $\begin{array}{l}\text { Images of } \\
\text { Bread }\end{array}$ & $\begin{array}{c}\text { K-Means } \\
\text { Seg. }\end{array}$ & $\begin{array}{c}\text { MCKM } \\
\text { Seg. }\end{array}$ & $\begin{array}{c}\text { FEKM } \\
\text { Seg. }\end{array}$ & $\begin{array}{c}\text { FECA } \\
\text { Seg. }\end{array}$ \\
\hline 2_400.jpg & 0.779 & 0.831 & 0.991 & 0.771 \\
5_400.jpeg & 0.272 & 0.479 & 0.346 & 0.475 \\
$\begin{array}{l}\text { Ddbread.pn } \\
\text { g }\end{array}$ & 0.592 & 0.234 & 0.363 & 0.193 \\
$\begin{array}{l}\text { Ddbread2.p } \\
\text { ng }\end{array}$ & 0.341 & 0.314 & 0.307 & 0.212 \\
\hline
\end{tabular}

(k) SC on different images of bread (with $\mathrm{K}=2$ )

\begin{tabular}{lcccc}
\hline $\begin{array}{l}\text { Images of } \\
\text { Bread }\end{array}$ & $\begin{array}{c}\text { K-Means } \\
\text { Seg. }\end{array}$ & $\begin{array}{c}\text { MCKM } \\
\text { Seg. }\end{array}$ & $\begin{array}{c}\text { FEKM } \\
\text { Seg. }\end{array}$ & $\begin{array}{c}\text { FECA } \\
\text { Seg. }\end{array}$ \\
\hline 2_400.jpg & 0.536 & 0.785 & 0.602 & 0.531 \\
& &
\end{tabular}




\begin{tabular}{lllll} 
5_400.jpeg & 3.391 & 2.667 & 1.505 & 0.660 \\
Ddbread.png & 0.738 & 0.998 & 0.788 & 0.670 \\
$\begin{array}{l}\text { Ddbread2.pn } \\
\text { g }\end{array}$ & 1.727 & 1.511 & 0.935 & 0.718 \\
\hline
\end{tabular}

(l) SC on different images of bread (with $\mathrm{K}=3$ )

\begin{tabular}{lcccc}
\hline $\begin{array}{l}\text { Images of } \\
\text { Bread }\end{array}$ & $\begin{array}{c}\text { K-Means } \\
\text { Seg. }\end{array}$ & $\begin{array}{c}\text { MCKM } \\
\text { Seg. }\end{array}$ & $\begin{array}{c}\text { FEKM } \\
\text { Seg. }\end{array}$ & $\begin{array}{c}\text { FECA } \\
\text { Seg. }\end{array}$ \\
\hline 2_400.jpg & 0.995 & 0.849 & 0.898 & 0.599 \\
5_400.jpeg & 0.685 & 0.771 & 0.991 & 0.766 \\
Ddbread.pn & 1.411 & 0.725 & 0.856 & 0.626 \\
g & & 0.902 & 0.803 & 0.712 \\
$\begin{array}{l}\text { Ddbread2.p } \\
\text { ng }\end{array}$ & 0.740 & 0 & \\
\hline
\end{tabular}

Keeping $K$ as 2 for all considered image segmentation methods and using MSE, RMSE, MAE, NAE and SC as evaluating parameters for testing the effectiveness of segmented result on different captured images of breads, it is observed that FECA-based segmentation technique produces minimum value of all considered performance parameters for most of the input images as compared to other segmented methods. This is also true when the value of $K$ was increased to three, as shown in Table I (a) to (d) and (g) to (l) respectively. And when the evaluation was done considering PSNR, we observed that FECA-based segmentation generates maximum value for most of the bread images for both gray-scale and three-colored segmentation as compared to other techniques. This can be observer from Table I (e) and (f) respectively. This indicates superior results for FECA-based segmentation approach and the prospect of detecting foreign particles on breads can be clearly concluded. Only the segmented image for 5_400.jpeg shows some discrepancy in few parameters. Therefore, we suggest in such cases to consider both FECA-segmented gray-scale and three-colored images to spot the presence of fungus on their surface. While for bread images of 2_400.jpg, Ddbread.png and Ddbread2.png, either two or three-colored segmented result of FECA is fruitful.

\section{ii. Experiment 2:}

The second experiment was carried out by capturing images of different quality of cheese. Some images were selected which already contained some patches of fungus in them. Those were considered as trial images in order to check whether the segmented methods accurately detect the presence of fungus on the cheese surface as originally present. The original images were segmented into their gray-scale and three-colour forms and their quality were tested by using the discussed performance measures. The results achieved are as follows:

Table II:

(a) MSE on different images of cheese (with $\mathrm{K}=2$ )

\begin{tabular}{lcccc}
\hline $\begin{array}{l}\text { Images of } \\
\text { Bread }\end{array}$ & $\begin{array}{c}\text { K-Means } \\
\text { Seg. }\end{array}$ & $\begin{array}{c}\text { MCKM } \\
\text { Seg. }\end{array}$ & $\begin{array}{c}\text { FEKM } \\
\text { Seg. }\end{array}$ & $\begin{array}{c}\text { FECA } \\
\text { Seg. }\end{array}$ \\
\hline Chh_400.jpg & 4.420 & 4.410 & 4.368 & 4.370 \\
Ch_400.jpg & 9.513 & 9.511 & 8.443 & 5.580 \\
Chse_400.jpg & 4.223 & 4.281 & 4.227 & 4.125 \\
\hline
\end{tabular}

(b) MSE on different images of cheese (with $\mathrm{K}=3$ )

\begin{tabular}{lcccc}
\hline $\begin{array}{l}\text { Images of } \\
\text { Bread }\end{array}$ & $\begin{array}{c}\text { K-Means } \\
\text { Seg. }\end{array}$ & $\begin{array}{c}\text { MCKM } \\
\text { Seg. }\end{array}$ & $\begin{array}{c}\text { FEKM } \\
\text { Seg. }\end{array}$ & $\begin{array}{c}\text { FECA } \\
\text { Seg. }\end{array}$ \\
\hline Chh_400.jpg & 3.301 & 5.040 & 4.023 & 3.035 \\
Ch_400.jpg & 13.575 & 4.172 & 4.268 & 2.439 \\
Chse_400.jpg & 7.462 & 3.140 & 3.117 & 2.486 \\
\hline
\end{tabular}

(c) RMSE on different images of cheese (with $\mathrm{K}=2$ )

\begin{tabular}{lcccc}
\hline $\begin{array}{l}\text { Images of } \\
\text { Bread }\end{array}$ & $\begin{array}{c}\text { K-Means } \\
\text { Seg. }\end{array}$ & $\begin{array}{c}\text { MCKM } \\
\text { Seg. }\end{array}$ & $\begin{array}{c}\text { FEKM } \\
\text { Seg. }\end{array}$ & $\begin{array}{c}\text { FECA } \\
\text { Seg. }\end{array}$ \\
\hline Chh_400.jpg & 2.102 & 2.172 & 2.116 & 1.090 \\
Ch_400.jpg & 3.284 & 3.084 & 2.838 & 2.362 \\
Chse_400.jpg & 2.055 & 2.086 & 2.101 & 2.031 \\
\hline
\end{tabular}

(d) RMSE on different images of cheese (with $\mathrm{K}=3$ )

\begin{tabular}{lcccc}
\hline $\begin{array}{l}\text { Images of } \\
\text { Bread }\end{array}$ & $\begin{array}{c}\text { K-Means } \\
\text { Seg. }\end{array}$ & $\begin{array}{c}\text { MCKM } \\
\text { Seg. }\end{array}$ & $\begin{array}{c}\text { FEKM } \\
\text { Seg. }\end{array}$ & $\begin{array}{c}\text { FECA } \\
\text { Seg. }\end{array}$ \\
\hline Chh_400.jpg & 1.817 & 4.247 & 2.671 & 1.483 \\
Ch_400.jpg & 5.794 & 2.439 & 2.985 & 2.026 \\
Chse_400.jpg & 6.120 & 1.772 & 1.642 & 1.576 \\
\hline
\end{tabular}

(e) PSNR on different images of cheese (with $\mathrm{K}=2$ )

\begin{tabular}{lcccc}
\hline $\begin{array}{l}\text { Images of } \\
\text { Bread }\end{array}$ & $\begin{array}{c}\text { K-Means } \\
\text { Seg. }\end{array}$ & $\begin{array}{c}\text { MCKM } \\
\text { Seg. }\end{array}$ & $\begin{array}{c}\text { FEKM } \\
\text { Seg. }\end{array}$ & $\begin{array}{c}\text { FECA } \\
\text { Seg. }\end{array}$ \\
\hline Chh_400.jpg & 41.676 & 41.406 & 41.523 & 41.725 \\
Ch_400.jpg & 37.419 & 38.347 & 38.922 & 40.664 \\
Chse_400.jpg & 41.874 & 42.073 & 42.287 & 42.976 \\
\hline
\end{tabular}

(f) PSNR on different images of cheese (with $\mathrm{K}=3$ )

\begin{tabular}{lcccc}
\hline $\begin{array}{l}\text { Images of } \\
\text { Bread }\end{array}$ & $\begin{array}{c}\text { K-Means } \\
\text { Seg. }\end{array}$ & $\begin{array}{c}\text { MCKM } \\
\text { Seg. }\end{array}$ & $\begin{array}{c}\text { FEKM } \\
\text { Seg. }\end{array}$ & $\begin{array}{c}\text { FECA } \\
\text { Seg. }\end{array}$ \\
\hline Chh_400.jpg & 42.943 & 35.568 & 43.127 & 44.180 \\
Ch_400.jpg & 32.870 & 41.926 & 40.952 & 42.384 \\
Chse_400.jpg & 32.394 & 43.161 & 42.422 & 44.175 \\
\hline
\end{tabular}

(g) MAE on different images of cheese (with $K=2$ )

\begin{tabular}{lcccc}
\hline $\begin{array}{l}\text { Images of } \\
\text { Bread }\end{array}$ & $\begin{array}{c}\text { K-Means } \\
\text { Seg. }\end{array}$ & $\begin{array}{c}\text { MCKM } \\
\text { Seg. }\end{array}$ & $\begin{array}{c}\text { FEKM } \\
\text { Seg. }\end{array}$ & $\begin{array}{c}\text { FECA } \\
\text { Seg. }\end{array}$ \\
\hline Chh_400.jpg & 63.443 & 63.946 & 63.365 & 60.350 \\
Ch_400.jpg & 74.811 & 74.806 & 70.178 & 59.384 \\
Chse_400.jpg & 57.475 & 55.621 & 54.924 & 49.056 \\
\hline
\end{tabular}

(h) MAE on different images of cheese (with $\mathrm{K}=3$ )

\begin{tabular}{lcccc}
\hline $\begin{array}{l}\text { Images of } \\
\text { Bread }\end{array}$ & $\begin{array}{c}\text { K-Means } \\
\text { Seg. }\end{array}$ & $\begin{array}{c}\text { MCKM } \\
\text { Seg. }\end{array}$ & $\begin{array}{c}\text { FEKM } \\
\text { Seg. }\end{array}$ & $\begin{array}{c}\text { FECA } \\
\text { Seg. }\end{array}$ \\
\hline Chh_400.jpg & 64.783 & 117.011 & 48.083 & 59.573 \\
Ch_400.jpg & 167.627 & 68.952 & 66.482 & 60.799 \\
Chse_400.jpg & 86.648 & 38.990 & 38.062 & 34.890 \\
\hline
\end{tabular}

(i) NAE on different images of cheese (with $\mathrm{K}=2$ )

\begin{tabular}{lcccc}
\hline $\begin{array}{l}\text { Images of } \\
\text { Bread }\end{array}$ & $\begin{array}{c}\text { K-Means } \\
\text { Seg. }\end{array}$ & $\begin{array}{c}\text { MCKM } \\
\text { Seg. }\end{array}$ & $\begin{array}{c}\text { FEKM } \\
\text { Seg. }\end{array}$ & $\begin{array}{c}\text { FECA } \\
\text { Seg. }\end{array}$ \\
\hline Chh_400.jpg & 0.336 & 0.456 & 0.579 & 0.334 \\
Ch_400.jpg & 0.512 & 0.366 & 0.455 & 0.290 \\
Chse_400.jpg & 0.922 & 0.759 & 0.509 & 0.310 \\
\hline
\end{tabular}

(j) NAE on different images of cheese (with $\mathrm{K}=3$ )

\begin{tabular}{lcccc}
\hline $\begin{array}{l}\text { Images of } \\
\text { Bread }\end{array}$ & $\begin{array}{c}\text { K-Means } \\
\text { Seg. }\end{array}$ & $\begin{array}{c}\text { MCKM } \\
\text { Seg. }\end{array}$ & $\begin{array}{c}\text { FEKM } \\
\text { Seg. }\end{array}$ & $\begin{array}{c}\text { FECA } \\
\text { Seg. }\end{array}$ \\
\hline Chh_400.jpg & 0.258 & 0.620 & 0.426 & 0.135 \\
Ch_400.jpg & 0.821 & 0.981 & 0.734 & 0.297 \\
Chse_400.jpg & 1.044 & 0.918 & 0.283 & 0.708 \\
\hline
\end{tabular}

(k) SC on different images of cheese (with $\mathrm{K}=2$ ) 


\begin{tabular}{lcccc}
\hline $\begin{array}{l}\text { Images of } \\
\text { Bread }\end{array}$ & $\begin{array}{c}\text { K-Means } \\
\text { Seg. }\end{array}$ & $\begin{array}{c}\text { MCKM } \\
\text { Seg. }\end{array}$ & $\begin{array}{c}\text { FEKM } \\
\text { Seg. }\end{array}$ & $\begin{array}{c}\text { FECA } \\
\text { Seg. }\end{array}$ \\
\hline Chh_400.jpg & 0.600 & 0.904 & 0.785 & 0.595 \\
Ch_400.jpg & 0.730 & 0.812 & 0.606 & 0.790 \\
Chse_400.jpg & 0.967 & 0.843 & 0.799 & 0.825 \\
\hline
\end{tabular}

(l) SC on different images of cheese (with $\mathrm{K}=3$ )

\begin{tabular}{lcccc}
\hline $\begin{array}{l}\text { Images of } \\
\text { Bread }\end{array}$ & $\begin{array}{c}\text { K-Means } \\
\text { Seg. }\end{array}$ & $\begin{array}{c}\text { MCKM } \\
\text { Seg. }\end{array}$ & $\begin{array}{c}\text { FEKM } \\
\text { Seg. }\end{array}$ & $\begin{array}{c}\text { FECA } \\
\text { Seg. }\end{array}$ \\
\hline Ch__400.jpg & 0.672 & 1.059 & 0.956 & 0.614 \\
Ch_400.jpg & 2.815 & 0.975 & 0.908 & 0.776 \\
Chse_400.jpg & 3.615 & 3.985 & 4.453 & 5.024 \\
\hline
\end{tabular}

PSNR is intended to evaluate the image quality which may be distracted due to the presence of noise in them. When our experiment was conducted using this performance parameter for image evaluation, as per our expectation we obtained larger values of it for almost all images of cheese by using FECA-based segmentation for both outputs of gray scale and colour images. This can be witnessed from Table II (e) and (f) respectively. For MSE, RMSE, MAE, NAE and SC where a lesser value implies better segmentation, we obtained their smaller values for most segmented cheese images using FECA-based segmentation keeping both $K$ as 2 and 3 respectively. This can be viewed from Table II (a) to (d) and (g) to (l) respectively. All these experimental results conducted on different images of cheese imply that even mild presence of fungal infection on the surface of cheese can be well traced out using FECA-based segmentation approach.

\section{iii. Experiment 3:}

The third experiment was conducted on cake images. Cakes which are available in different colors, varieties and shapes make it quite intricate to identify if there exists any fungus particles on their surface. Hence, it requires utmost precision to trace out those foreign particles. The considered algorithms were able to fragment the original images into two and three-colored segmented images as per the users' need. Then the output image qualities were evaluated to determine their efficacy which is as follows:

Table III:

(a) MSE on different images of cake (with $\mathrm{K}=2$ )

\begin{tabular}{lcccc}
\hline $\begin{array}{l}\text { Images of } \\
\text { Bread }\end{array}$ & $\begin{array}{c}\text { K-Means } \\
\text { Seg. }\end{array}$ & $\begin{array}{c}\text { MCKM } \\
\text { Seg. }\end{array}$ & $\begin{array}{c}\text { FEKM } \\
\text { Seg. }\end{array}$ & $\begin{array}{c}\text { FECA } \\
\text { Seg. }\end{array}$ \\
\hline Cake_400.jpg & 24.368 & 10.385 & 11.521 & 10.400 \\
Ck_400.jpg & 26.631 & 21.402 & 20.004 & 18.116 \\
\hline
\end{tabular}

(b) MSE on different images of cake (with $\mathrm{K}=3$ )

\begin{tabular}{lcccc}
\hline $\begin{array}{l}\text { Images of } \\
\text { Bread }\end{array}$ & $\begin{array}{c}\text { K-Means } \\
\text { Seg. }\end{array}$ & $\begin{array}{c}\text { MCKM } \\
\text { Seg. }\end{array}$ & $\begin{array}{c}\text { FEKM } \\
\text { Seg. }\end{array}$ & $\begin{array}{c}\text { FECA } \\
\text { Seg. }\end{array}$ \\
\hline Cake_400.jpg & 20.429 & 11.929 & 12.663 & 13.328 \\
Ck_400.jpg & 16.562 & 14.873 & 14.941 & 13.017 \\
\hline
\end{tabular}

(c) RMSE on different images of cake (with $\mathrm{K}=2$ )

\begin{tabular}{lcccc}
\hline $\begin{array}{l}\text { Images of } \\
\text { Bread }\end{array}$ & $\begin{array}{c}\text { K-Means } \\
\text { Seg. }\end{array}$ & $\begin{array}{c}\text { MCKM } \\
\text { Seg. }\end{array}$ & $\begin{array}{c}\text { FEKM } \\
\text { Seg. }\end{array}$ & $\begin{array}{c}\text { FECA } \\
\text { Seg. }\end{array}$ \\
\hline Cake_400.jpg & 4.936 & 3.292 & 3.268 & 3.220 \\
Ck_400.jpg & 8.632 & 6.023 & 6.995 & 5.471 \\
\hline
\end{tabular}

(d) RMSE on different images of cake (with $\mathrm{K}=3$ )

\begin{tabular}{lcccc}
\hline $\begin{array}{l}\text { Images of } \\
\text { Bread }\end{array}$ & $\begin{array}{c}\text { K-Means } \\
\text { Seg. }\end{array}$ & $\begin{array}{c}\text { MCKM } \\
\text { Seg. }\end{array}$ & $\begin{array}{c}\text { FEKM } \\
\text { Seg. }\end{array}$ & $\begin{array}{c}\text { FECA } \\
\text { Seg. }\end{array}$ \\
\hline Cake_400.jpg & 4.519 & 3.453 & 3.372 & 3.150 \\
Ck_400.jpg & 5.144 & 6.645 & 6.018 & 4.636 \\
\hline
\end{tabular}

(e) PSNR on different images of cake (with $\mathrm{K}=2$ )

\begin{tabular}{lcccc}
\hline $\begin{array}{l}\text { Images of } \\
\text { Bread }\end{array}$ & $\begin{array}{c}\text { K-Means } \\
\text { Seg. }\end{array}$ & $\begin{array}{c}\text { MCKM } \\
\text { Seg. }\end{array}$ & $\begin{array}{c}\text { FEKM } \\
\text { Seg. }\end{array}$ & $\begin{array}{c}\text { FECA } \\
\text { Seg. }\end{array}$ \\
\hline Cake_400.jpg & 34.262 & 36.966 & 38.011 & 37.960 \\
Ck_400.jpg & 42.441 & 39.062 & 43.627 & 44.869 \\
\hline
\end{tabular}

(f) PSNR on different images of cake (with $K=3$ )

\begin{tabular}{lcccc}
\hline $\begin{array}{l}\text { Images of } \\
\text { Bread }\end{array}$ & $\begin{array}{c}\text { K-Means } \\
\text { Seg. }\end{array}$ & $\begin{array}{c}\text { MCKM } \\
\text { Seg. }\end{array}$ & $\begin{array}{c}\text { FEKM } \\
\text { Seg. }\end{array}$ & $\begin{array}{c}\text { FECA } \\
\text { Seg. }\end{array}$ \\
\hline Cake_400.jpg & 35.028 & 37.364 & 38.158 & 36.882 \\
Ck_400.jpg & 41.369 & 46.902 & 49.663 & 51.043 \\
\hline
\end{tabular}

(g) MAE on different images of cake (with $\mathrm{K}=2$ )

\begin{tabular}{lcccc}
\hline $\begin{array}{l}\text { Images of } \\
\text { Bread }\end{array}$ & $\begin{array}{c}\text { K-Means } \\
\text { Seg. }\end{array}$ & $\begin{array}{c}\text { MCKM } \\
\text { Seg. }\end{array}$ & $\begin{array}{c}\text { FEKM } \\
\text { Seg. }\end{array}$ & $\begin{array}{c}\text { FECA } \\
\text { Seg. }\end{array}$ \\
\hline Cake_400.jpg & 154.917 & 100.082 & 123.227 & 100.144 \\
Ck_400.jpg & 82.121 & 74.225 & 70.179 & 66.482 \\
\hline
\end{tabular}

(h) MAE on different images of cake (with $\mathrm{K}=3$ )

\begin{tabular}{lcccc}
\hline $\begin{array}{l}\text { Images of } \\
\text { Bread }\end{array}$ & $\begin{array}{c}\text { K-Means } \\
\text { Seg. }\end{array}$ & $\begin{array}{c}\text { MCKM } \\
\text { Seg. }\end{array}$ & $\begin{array}{c}\text { FEKM } \\
\text { Seg. }\end{array}$ & $\begin{array}{c}\text { FECA } \\
\text { Seg. }\end{array}$ \\
\hline Cake_400.jpg & 137.513 & 99.734 & 98.539 & 95.854 \\
Ck_400.jpg & 124.443 & 116.027 & 110.632 & 102.227 \\
\hline
\end{tabular}

(i) NAE on different images of cake (with $\mathrm{K}=2$ )

\begin{tabular}{lcccc}
\hline $\begin{array}{l}\text { Images of } \\
\text { Bread }\end{array}$ & $\begin{array}{c}\text { K-Means } \\
\text { Seg. }\end{array}$ & $\begin{array}{c}\text { MCKM } \\
\text { Seg. }\end{array}$ & $\begin{array}{c}\text { FEKM } \\
\text { Seg. }\end{array}$ & $\begin{array}{c}\text { FECA } \\
\text { Seg. }\end{array}$ \\
\hline Cake_400.jpg & 1.070 & 0.891 & 0.552 & 0.661 \\
Ck_400.jpg & 0.619 & 0.549 & 0.498 & 0.412 \\
\hline
\end{tabular}

(j) NAE on different images of cake (with $\mathrm{K}=3$ )

\begin{tabular}{lcccc}
\hline $\begin{array}{l}\text { Images of } \\
\text { Bread }\end{array}$ & $\begin{array}{c}\text { K-Means } \\
\text { Seg. }\end{array}$ & $\begin{array}{c}\text { MCKM } \\
\text { Seg. }\end{array}$ & $\begin{array}{c}\text { FEKM } \\
\text { Seg. }\end{array}$ & $\begin{array}{c}\text { FECA } \\
\text { Seg. }\end{array}$ \\
\hline Cake_400.jpg & 0.950 & 0.689 & 0.508 & 0.730 \\
Ck_400.jpg & 0.701 & 0.796 & 0.845 & 0.624 \\
\hline
\end{tabular}

(k) SC on different images of cake (with $\mathrm{K}=2$ )

\begin{tabular}{lcccc}
\hline $\begin{array}{l}\text { Images of } \\
\text { Bread }\end{array}$ & $\begin{array}{c}\text { K-Means } \\
\text { Seg. }\end{array}$ & $\begin{array}{c}\text { MCKM } \\
\text { Seg. }\end{array}$ & $\begin{array}{c}\text { FEKM } \\
\text { Seg. }\end{array}$ & $\begin{array}{c}\text { FECA } \\
\text { Seg. }\end{array}$ \\
\hline Cake_400.jpg & 2.843 & 1.379 & 1.224 & 0.398 \\
Ck_400.jpg & 1.993 & 1.804 & 1.736 & 0.954 \\
\hline
\end{tabular}

\section{(l) SC on different images of cake (with $\mathrm{K}=3$ )}

\begin{tabular}{lcccc}
\hline $\begin{array}{l}\text { Images of } \\
\text { Bread }\end{array}$ & $\begin{array}{c}\text { K-Means } \\
\text { Seg. }\end{array}$ & $\begin{array}{c}\text { MCKM } \\
\text { Seg. }\end{array}$ & $\begin{array}{c}\text { FEKM } \\
\text { Seg. }\end{array}$ & $\begin{array}{c}\text { FECA } \\
\text { Seg. }\end{array}$ \\
\hline Cake_400.jpg & 0.850 & 0.669 & 0.572 & 0.705 \\
Ck_400.jpg & 1.815 & 1.902 & 1.367 & 1.103 \\
\hline
\end{tabular}

Many images of cakes were experimented however, we have presented two varieties of it in this paper. Similar types of outcome as obtained from Experiment 1 and 2 are also found here. All the numerical values obtained from the performance measure for different indices signify that FECA-based segmentation is best suited for identification of fungus in cakes as confirmed from Table III (a) to (l) respectively. Although there is some discrimination for Cake_400.jpg image but almost all values for Ck_400.jpg gives satisfactory results. Hence, fungus may be detected from Ck_400.jpg by opting either from its segmented gray-scale or colour portion. However, for Cake_400.jpg we may employ both its gray-scale and three colour partitions for

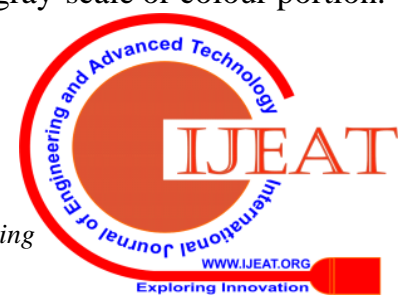


effectively discovering the presence of fungus in it.

The computation time of all the segmentation algorithms were evaluated. K-Means-based segmentation takes less time to converse whereas the other discussed methods take slightly more time than K-Means to meet their convergence criteria. All algorithms were implemented using $5^{\text {th }}$ Gen Intel ${ }^{\circledR}$ core i3 Processor, frequency1.90 Ghz. with 4 GB RAM machine. The execution time of different algorithms implemented on images of different varieties of food items are shown below in Table IV (a) and (b).

Table IV:

(a) Running time (in sec.) of all considered segmentation algorithms on different food images (with $\mathrm{K}=2$ )

\begin{tabular}{lcccc}
\hline $\begin{array}{l}\text { Food Item } \\
\text { Image }\end{array}$ & $\begin{array}{c}\text { K-Means } \\
\text { Seg. }\end{array}$ & $\begin{array}{c}\text { MCKM } \\
\text { Seg. }\end{array}$ & $\begin{array}{c}\text { FEKM } \\
\text { Seg. }\end{array}$ & $\begin{array}{c}\text { FECA } \\
\text { Seg. }\end{array}$ \\
\hline 2_400.jpg & 4.931 & 4.078 & 4.026 & 5.011 \\
5_400.jpeg & 3.485 & 3.507 & 4.051 & 4.886 \\
Cake_400.jpg & 3.965 & 3.511 & 3.645 & 4.023 \\
Chh_400.jpg & 2.461 & 2.924 & 2.991 & 3.104 \\
Ch_400.jpg & 1.278 & 1.308 & 1.983 & 2.565 \\
Ddbread.png & 4.926 & 3.054 & 3.509 & 4.212 \\
Ddbread2.png & 3.078 & 3.724 & 3.989 & 4.352 \\
Chse_400.jpg & 3.271 & 2.614 & 3.872 & 3.909 \\
\hline
\end{tabular}

Table IV:

(b) Running time (in sec.) of all considered segmentation algorithms on different food images (with $\mathrm{K}=3$ )

\begin{tabular}{lcccc}
\hline $\begin{array}{l}\text { Food Item } \\
\text { Image }\end{array}$ & $\begin{array}{c}\text { K-Means } \\
\text { Seg. }\end{array}$ & $\begin{array}{c}\text { MCKM } \\
\text { Seg. }\end{array}$ & $\begin{array}{c}\text { FEKM } \\
\text { Seg. }\end{array}$ & $\begin{array}{c}\text { FECA } \\
\text { Seg. }\end{array}$ \\
\hline 2_400.jpg & 5.221 & 5.509 & 5.668 & 5.926 \\
5_400.jpeg & 4.044 & 4.606 & 4.446 & 5.772 \\
Cake_400.jpg & 4.571 & 4.373 & 4.956 & 5.603 \\
Chh_400.jpg & 3.190 & 3.912 & 4.402 & 4.961 \\
Ch_400.jpg & 3.278 & 2.132 & 3.606 & 4.253 \\
Ddbread.png & 4.121 & 4.210 & 4.812 & 5.394 \\
Ddbread2.png & 4.816 & 4.822 & 5.226 & 5.862 \\
Chse_400.jpg & 3.615 & 3.985 & 4.453 & 5.024 \\
\hline
\end{tabular}

\section{OBSERVATIONS}

Experiments were conducted for the formation of diverse colour groups taking different values of $K$. This was done to 5_400 clearly identify the existence of a slighter formation of fungal growth on food items. For this reason, we segment them by taking $K=2$, 3, 4 etc. to obtain gray scale, three-coloured, four-coloured groups etc. However, in this paper we have shown only segmentation results with $K=2$ and 3 . When $K=2$, we get the gray scale image of the original one where one cake_400 cluster shows the presence of fungus on food surface and the other confirms their absence. When $K=3$, the fungal part is separated from the remaining parts and the background. These observations are shown in Fig. 2 (b) and (c) for FECA based segmentation. Similarly, Fig. 3(b) and (c) confers the segmentation result obtained using K-Means by considering ${ }^{\text {ch_4 } 400}$ $K=2$ and $K=3$ respectively and Fig. 3 (d) and (e) presents the segmentation achieved by MCKM based segmentation considering both $K=2$ and 3 .

Approximately all values of performance measures considered illustrates better outcome for image segmentation using FECA, which was our expectation. Hence, the chances of detecting the presence of early fungal growth on food products are quite high with FECA. But, it takes comparatively a few seconds more to meet its convergence.

Both K-Means and MCKM meet their convergence a little earlier than the other two methods for both gray scale and segmented colour images as seen from Table IV (a) and (b). However, MCKM could be sometimes computationally expensive if used for higher resolution images because it computes the Euclidean distances from all pixels to the initial pixel, then sorting them and storing them in ascending order in the very first step of the algorithm. Similar case is true for FEKM where the initial centers are computed. Conversely, K-Means is effective in meeting its convergence slightly earlier as the initial centers are randomly chosen but, may at times give drastic result if the centers are wrongly initialized.

One more thing that can be observer from the experiment conducted on frequently consumed food products that, in most cases the fungal detection on their surfaces can be effectively traced from either their gray-scale or three-coloured segmented images using FECA however, in some images their presence cannot be clearly determined. This may be due to the fact that the images captured may be noisy, blurred and unclear. Hence, for few such cases we suggest to consider both their gray-scale and three-coloured segmented outputs for tracking. In addition to these observations we also found that, when the values of $K$ were increased to 4, 5 etc, the output segmented images produces ineffective results. The possibilities of tracing out the presence of any foreign particles on the food stuffs are imprecise. The performance measures also assured these facts. Another discouraging factor with the increase in $K$ values is the extra bit of seconds the algorithms take to converge. Hence, to resolve this issue we encourage to use two and three coloured segmentation for effectively detecting the fungal growth on food surfaces if any.

2_400
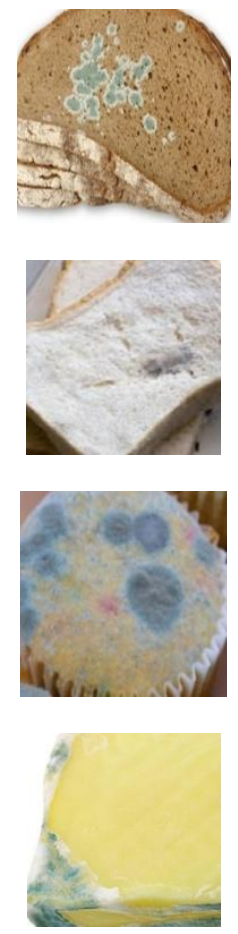
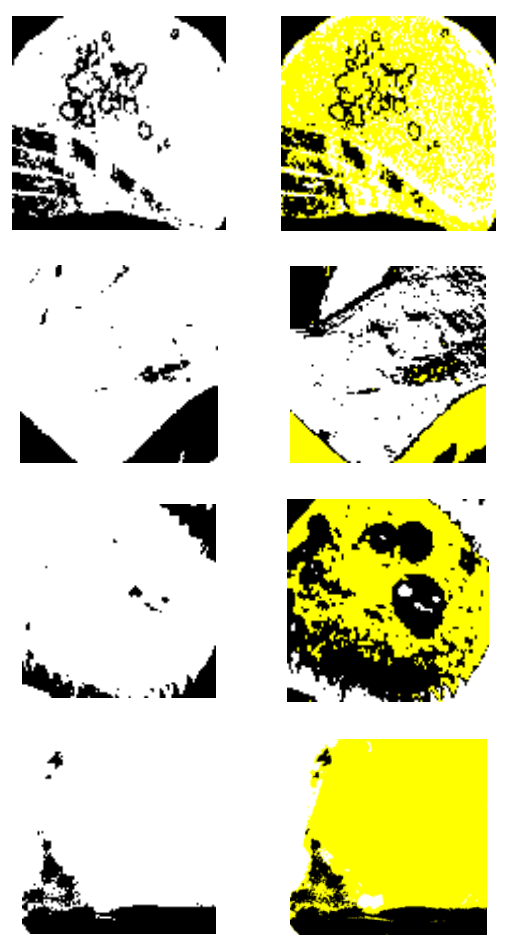


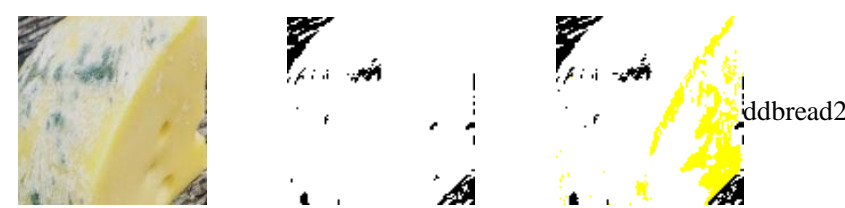

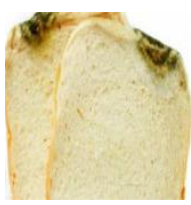

(a)

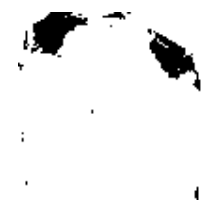

(b)

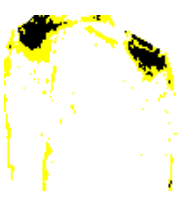

(c)

Fig. 2: (a) Original image, (b) and (c) Segmentation using FECA with $K=2$ and $K=3$
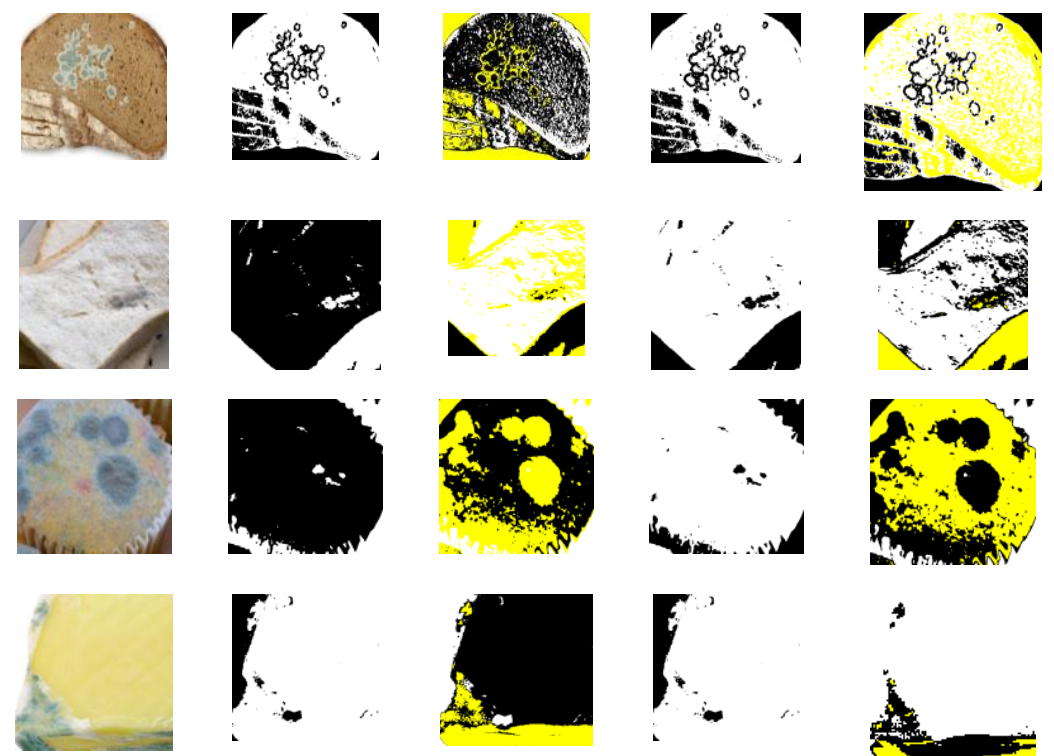

:
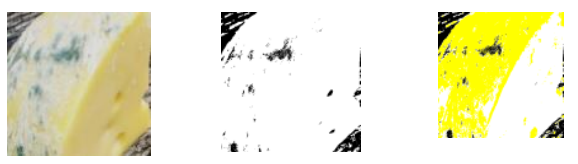

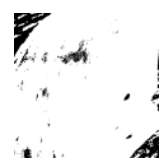
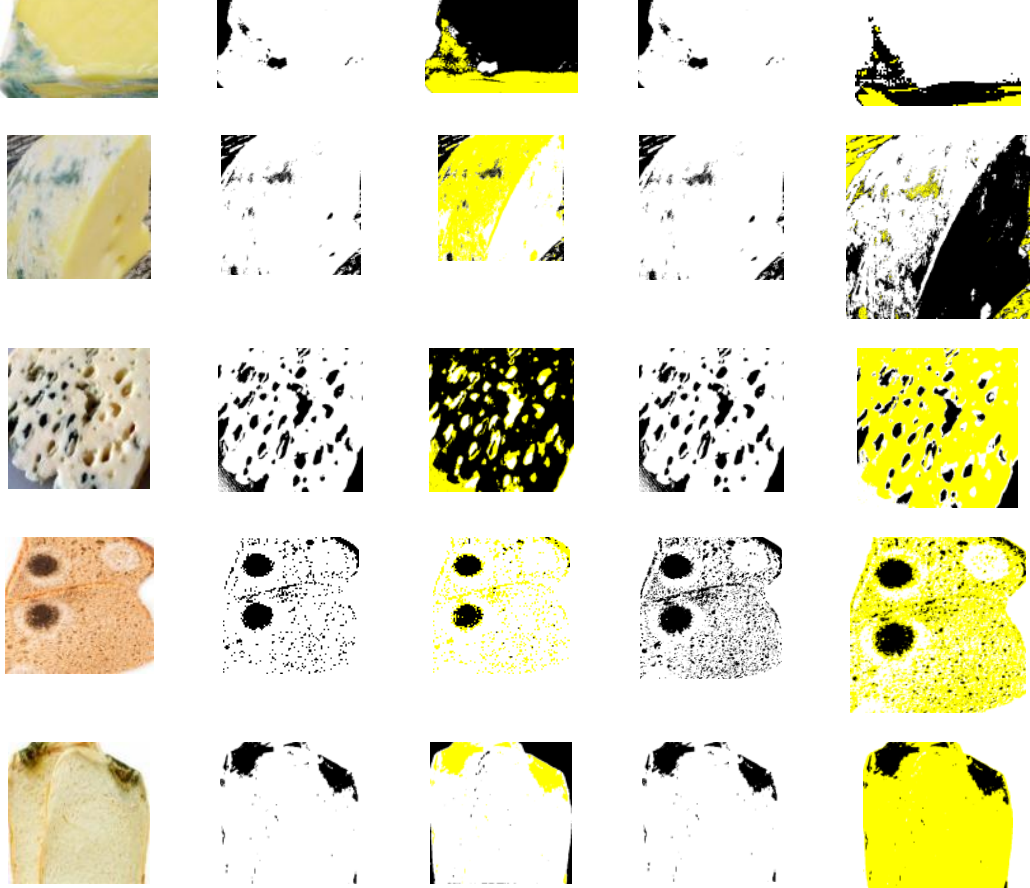

(c)

(d)
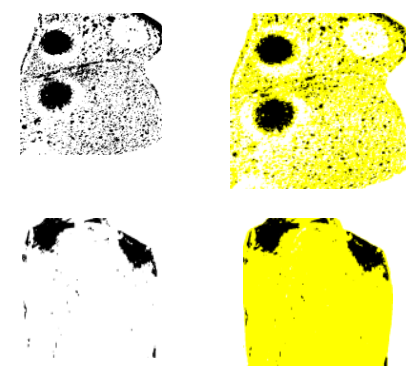

(e)

chse 400
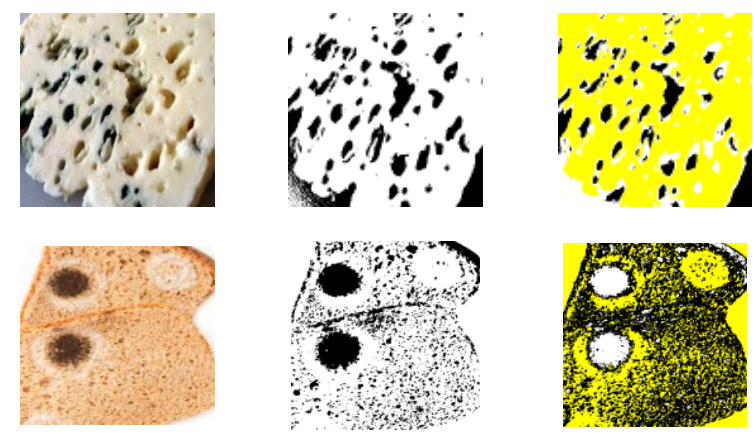

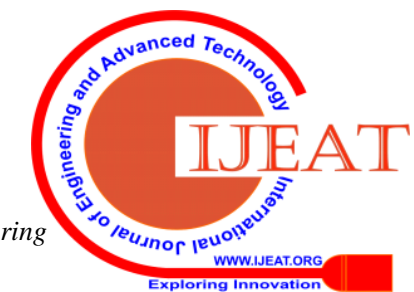


Fig. 3: (a) Original image

\section{(b) and (c) Segmentation using K-Means with $K=2$ and $K=3$ (d) and (e) Segmentation using MCKM with $K=2$ and $K=3$}

\section{CONCLUSION}

Image segmentation approach is one of the appropriate solutions by means of which any unsafe unfamiliar materials like fungus, yeast, mould etc. can be easily traced out from food surfaces. In this paper, we have considered K-Means, MCKM, FEKM and FECA cluster-based image segmentation algorithms to spot the image portion of food items where there may be some possible existence of fungal growth. The efficiency of the results attained by the discussed methods was assessed by means of few familiar performance measures including SC, RMSE, PSNR, MSE, MAE and NAE. After evaluating their segmentation results it can be concluded that, more or less all statistics of performance quality criteria produce better result of image segmentation using FECA based algorithm as compared to K-Means, MCKM, FEKM techniques which was our expectation. Hence, the likelihood of spotting any fungal growth on food items is relatively high with FECA and can be precisely used for this purpose. However, its computation time is a bit large with contrast to other methods. In this regard the conventional K-Means and to some extent its modified approach meets their convergence earlier.

We have further thought of expanding this work and compare it with other innovative methods for early recognition of food spoilage alongside commercial feasibility. We would also like to utilize it in other spheres of agriculture and society to develop our farming in smart way.

\section{REFERENCES}

1. Anwer, S. S., Ali, G. A., Hamadamin, C. and Jafar, H. Y. "Isolation and Identification of Fungi from Fast Food Restaurants in Langa Bazar". Int. J. of Environment, Agriculture and Biotechnology. vol. 2, issue - 4, pp. 1517 - 1522, 2017.

2. Beigi, T. M., Ngadi, M. O., Holman, D. B, and Chenier, M. R. Analysis of Fungal Diversity in Ready-to-Eat Pizza and Effectiveness of Pulsed Ultraviolet-Light Treatment for Inactivation of Mold on Agar Surface. Journal of Bioprocessing \& Biotechniques. vol. 5, no. 5, pp. 1-7, 2015.

3. Brosnan, T. and Sun D. "Improving Quality Inspection of Food Products by Computer Vision- A Review". Journal of Food Engineering, vol. 61, pp. 3-16, 2004.

4. Deshpande, T., Sengupta, S. and Raghuvanshi, K. S. "Grading \& Identification of Disease in Pomegranate Leaf and Fruit". Int. Journal of Computer Sc. \& Information Tech., vol. 5, issue 3, pp. 4638 - 4645, 2014.

5. Dubey, S. R., Dixit, P., Singh, N. and Gupta, J. P. "Infected Fruit Part Detection using K-Means Clustering Segmentation Technique", I. J. of Artificial Intel. \& Interactive Multimedia, vol. 2, no. 2, pp. 65- 72, 2013.

6. Gonzales, R., Woods, R. and Reinhard Klette. Digital image processing. Pearson education international, pp. 321 - 347, 2008.

7. Grillo, O., Rizzo, V., Saccone, R., Fallico, B., Mazzaglia, A., Venora, G., and Muratore, G. "Use of Image Analysis to Evaluate the Shelf Life of Bakery Products", Food Research Int., vol. 62, pp. 514 - 522, 2014.

8. Gupta, P. and Pahwa, K. "Colour Enhancement of Digital Image Based on Analysis of Individual Pixel". Int. J. of Computational Intelligence Studies, vol. 5, issue 3/4, pp. 252 - 266, 2016.

9. Kaur, J., Agarwal, S. and Vig, R. “A Methodology for the Performance Analysis of Cluster Based Image Segmentation”. Int. J. of Engineering Research and Applications, vol. 2, issue 2, pp. 664 - 667, 2012.

10. Keat, L. C., Ibrahim, M., Ariff, M. H., and Khatun, S. "Image Processing Analysis of Prevention for Mold Growth on Bread using Negative Ion Technology". Journal of Telecommunication, Electronic and Computer Engineering. vol. 10, no. 1 - 2, pp. 175 - 179, 2018.

11. Legan, J. D. and Voysey, P. A. Yeast Spoilage of Bakery Products and Ingredients. Journal of Applied Bacteriology, 70, pp. 361 - 371.

12. Mac Queen, J. (1967). "Some Methods for Classification and Analysis of Multivariate Observations". Fifth Berkeley Symposium on Mathematics, Statistics and Probability, pp. 281-297, University of California Press, 1991.
13. Madgi, M., Danti, A. and Anami, B. "Combined RGB Color and Local Binary Pattern Statistics Features-Based Classification and Identification of Vegetable Images". Int. J. of Applied Pattern Recognition, vol. 2, issue 4, pp. 340 - 352, 2015.

14. Mishra, B. K., Rath, A. K.., Nanda, S. K., and Baidyanath, R. R. "Efficient Intelligent Framework for Selection of Initial Cluster Centers", I.J. Intelligent Systems and Applications, vol. 11, no. 8, pp. 44-55, 2019.

15. Mishra, B. K. and Rath, A. K. "Improving the Efficacy of Clustering by Using Far Enhanced Clustering Algorithm”. Int. J. Data Mining, Modeling and Management, vol. 10, issue 3, pp. 269 - 292, 2018.

16. Mishra, B. K., Nayak, N. R., Rath, A. K. and Swain, S. "Far Efficient K-Means Clustering Algorithm. Int. Conference on Advances in Computing, Communications and Informatics, ACM, pp. 106 - 110, 2012.

17. Narendra, V. G. and Hareesh, K. S. "Quality Inspection and Grading of Agricultural and Food Products by Computer Vision - A Review". Int. Journal of Computer Applications. vol. 2, no. 1, pp. 43 - 65, 2010.

18. Poobal, S. and Ravindran, G. "The Performance of Fractal Image Compression on Different Imaging Modalities Using Objective Quality Measures". Int. J. of Engg. Science and Technology, vol. 3, no. 1, pp. 525 530, 2011.

19. Pujari, J. D., Yakkundimath, R. and Byadgi, A. S. "Image Processing Based Detection of Fungal Diseases in Plants". Procedia Computer Science, vol. 46, pp. 1802 - 1808, 2015.

20. Rajkumar. S and Malathi G. "A Comparative Analysis on Image Quality Assessment for Real Time Satellite Images". Indian Journal of Science and Technology, vol. 9 (34), pp. 1 - 11, 2016.

21. Saranraj, P. and Sivasakthivelan, P. "Microorganisms Involved in Spoilage of Bread and Its Control Measures". CRC press Taylor \& Francis Group, New York, pp. 132 - 149, 2015.

22. Tortorello, M. L. and Stewart, D. S. "Antibody-Direct Epifluorescent Filter Technique for Rapid, Direct Enumeration of Escherichia Coli 0157:H7 in Beef'. Applied \& Enviro. Microbiology, 60, pp. 3553 3559, 1994

23. Willmott, C. J. and Matsuura, K. "Advantages of the Mean Absolute Error (MAE) Over the Root Mean Square Error (RMSE) in Assessing Average Model Performance”. Climate Research, vol. 30, issue 1, pp. 79 - 82, 2005.

\section{AUTHORS PROFILE}

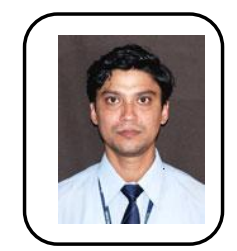

Bikram Keshari Mishra is currently working as a Professor in the Department of Computer Science and Engineering at VSSUT, Burla, India. He presently has active involvements with novel works involving data clustering and applications. His research interests focus on data mining, knowledge discovery and image processing.

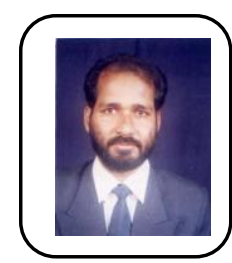

Amiya Kumar Rath is a Professor in the Department of Computer Science at VSSUT, Burla, India. Presently he is deputed to National Assessment and Accreditation Council (NAAC), Bangalore as adviser. He has contributed more than 70 research level papers to many national and international journals and conferences. His research interests include embedded system, ad-hoc network, evolutionary computation and data mining.

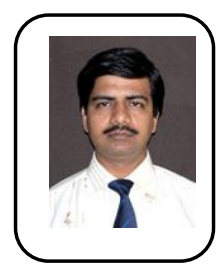

Pradyumna Kumar Tripathy has completed his M.Tech. and Ph.D. in Computer Science from Utkal University, India in 2007 and 2015 respectively. He is currently working as Associate Professor in the Dept. of Computer Sc. \& Engg. at Silicon Institute of Technology, Bhubaneswar, India.. His research interests include Reliability Analysis of Interconnection Networks, Parallel Distributed Systems and Topological Optimization of Interconnection Networks, Data Analysis.

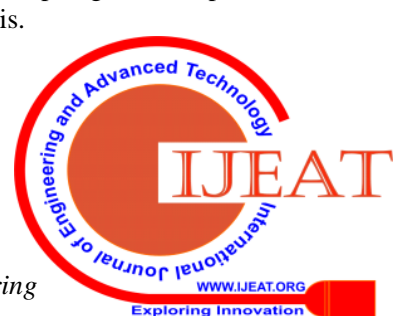

